\title{
Correction to: Renewable energy utilization to promote sustainability in GCC countries: policies, drivers, and barriers
}

\author{
Karim Malik ${ }^{1}$ - Syed Masiur Rahman ${ }^{2}$ (D) Abu Nasser Khondaker ${ }^{2}$ - Ismaila Rimi Abubakar ${ }^{3}$ - Yusuf Adedoyin Aina ${ }^{4}$. \\ Md Arif Hasan ${ }^{5}$
}

Published online: 15 August 2019

(C) Springer-Verlag GmbH Germany, part of Springer Nature 2019

\section{Correction to: Environmental Science and Pollution Research (2019) 26:20798-20814 https://doi.org/10.1007/s11356-019-05337-1}

1. In the abstract, the statement "The GHG emissions avoidance expected to be achieved by the GCC countries will vary between 5 and 247 million tons of $\mathrm{CO}_{2}$ equivalent by 2030." should be changed to "The GHG emissions avoidance expected to be achieved by the GCC countries will vary between 1 and 50 million tons of $\mathrm{CO}_{2}$ equivalent by 2030."

2. Figure 4 was revised and is shown in this paper.

3. The sentence "It appears that Saudi Arabia will be able to meet its NDC pledge even only relying on the RE target." from the section titled "Future RE contributions" should be removed from this paper.

4. In conclusion, the statement "The GHG emissions avoidance due to RE deployment will be approximately 247 ,

The online version of the original article can be found at https://doi.org/ 10.1007/s11356-019-05337-1

Syed Masiur Rahman

smrahman@kfupm.edu.sa

Karim Malik

mali3080@mylaurier.ca

Abu Nasser Khondaker nasserk@kfupm.edu.sa

Ismaila Rimi Abubakar irabubakar@iau.edu.sa

Yusuf Adedoyin Aina

ainay@ rcyci.edu.sa

Md Arif Hasan

arif_hasan_urp@yahoo.com

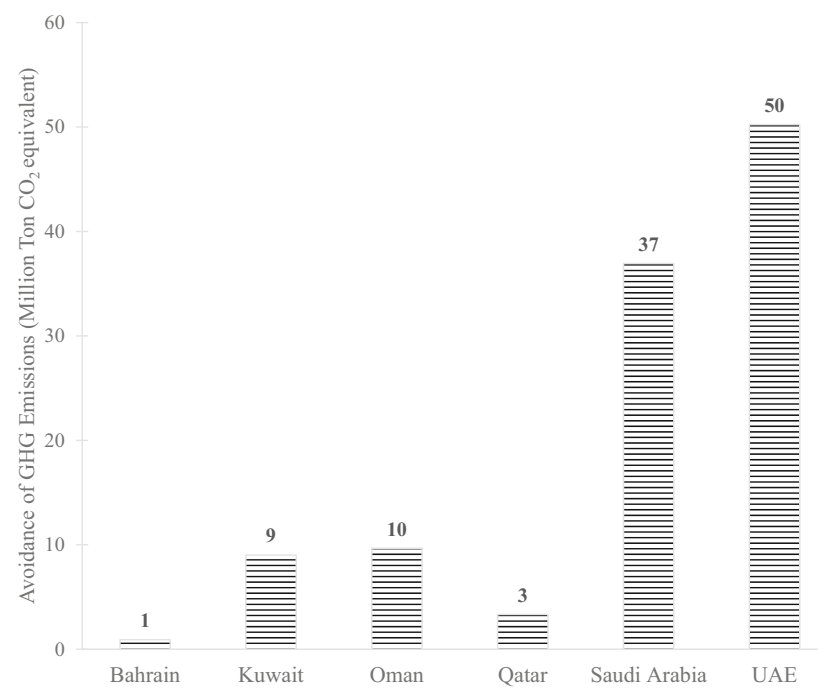

Fig. 4 Expected greenhouse gas emissions avoidance in GCC countries in 2030

1 Department of Geography and Environmental Studies, Wilfrid Laurier University, Waterloo, Canada

2 Center for Environment \& Water, Research Institute, King Fahd University of Petroleum \& Minerals, KFUPM Box 713, Dhahran 31261, Saudi Arabia

3 College of Architecture and Planning, Imam Abdulrahman Bin Faisal University (Formerly, University of Dammam), PO. Box 1982, Dammam 31441, Saudi Arabia

4 Department of Geomatics Engineering Technology, Yanbu Industrial College, Yanbu, Saudi Arabia

5 School of Geography, Environment and Earth Sciences, Victoria University of Wellington, Wellington 6140, New Zealand 
$175,45,45,16$, and 5 million tons of $\mathrm{CO}_{2}$ equivalent, for the UAE, Saudi Arabia, Oman, Kuwait, Qatar, and Bahrain, respectively by 2030 ." should be changed to "The GHG emissions avoidance due to RE deployment will be approximately 50,37, 10, 9, 3, and 1 million tons of $\mathrm{CO}_{2}$ equivalent, for the UAE, Saudi Arabia, Oman, Kuwait, Qatar, and Bahrain, respectively by 2030.”

Publisher's note Springer Nature remains neutral with regard to jurisdictional claims in published maps and institutional affiliations. 